\title{
Leaf Carbohydrates and Flower Formation in Citrus
}

\author{
A. Garcia-Luis, F. Fornes, and J.L. Guardiola \\ Departmento de Biologia Vegetal, Universidad Politécnica, 46071 Valencia, Spain
}

Additional index words. carbohydrate partitioning, Citrus unshiu, satsuma mandarin, starch

\begin{abstract}
The carbohydrate contents of the leaves of satsuma mandarin (Citrus unshiu Marc.) trees were altered before or during the low temperature flower induction period to determine the relationship between gross levels of carbohydrates and flower formation. Early removal of the fruit and girdling of the branches on either fruiting or defruited trees caused an accumulation of carbohydrates in the leaves and increased flower formation. Shading the trees resulted in a transient reduction in leaf carbohydrate levels and in a decrease in flower formation. Although a relationship between carbohydrate levels and flowering was consistently found, our results show that the gross levels of carbohydrates do not appear to limit flower formation in citrus.
\end{abstract}

When grown in subtropical climates, citrus produce flowers during the spring season following the winter rest period. Flowers arc formed from the axillary buds on wood less than 1 year old (Monselise, 1985; Davenport, 1990). Flower formation occurs in response to chilling temperatures, and the number of flowers formed can increase with the duration of exposure to low temperature (Moss, 1969; Southwick and Davenport, 1986). Chilling is perceived in the buds and has two separate effects, as it releases bud dormancy and induces flowering (Garcia-Luis et al., 1992a).

The number of flowers formed can be inversely related also to the number of fruit produced in the previous season (Moss, 1971; Becerra and Guardiola, 1984). A reduction in crop load before winter, either through the thinning of part of the fruits (Moss, 1971; Goldschmidt and Golomb, 1982) or through the advancement of harvest (Garcia-Luis et al., 1986), increases flowering during the following season.

Carbohydrate accumulation in the leaves and/or other tree organs results from chilling (Yelenosky and Guy, 1977; Guy et al., 1981) and the reduction in crop load (Jones et al., 1970; Lenz and Küntzel, 1974; Goldschmidt and Golomb, 1982). Positive correlations have been shown between carbohydrate accumulation and flowering, which has lead workers to assume that the levels of nonstructural carbohydrates may be a limiting factor in flower formation in citrus (Ogaki et al., 1963; Goldschmidt and Golomb, 1982; Lovatt et al., 1988). This view is supported by the fact that girdling can enhance flower formation (Cohen, 1981; Emer, 1988; Iwahori et al., 1990) and starch accumulation in the leaves (Furr and Annstrong, 1956; Fishler et al.. 1983). In some cases, however, a relationship between carbohydrate levels and flower formation could not be demonstrated (Lewis et al.. 1964; Goldschmidt et al.. 1985; Garcia-Luis et al., 1988). As pointed out by Davenport (1990), the association between carbohydrate (starch) levels and flowering is obscure, and cause-and-effect relationships have not been established.

The ob-jcctivcs of our investigation were to determine I) if carbohydrate levels in the leaves, either before winter chilling or during the chilling period, are related to flower formation and 2) if the inhibition of flower formation by the fruit or the enhancement of flower formation by girdling may be related to carbohydrate availability.

Received for publication 16 May 1994. Accepted for publication 12 Scpt. 1994 This research was funded by CICYT grant PB88-0358. We thank M. SánchéPerales for technical assistance. The cost of publishing this paper was defrayed in part by the payment of page charges. Under postal regulations, this paper therefore must be hereby marked advertisemen solcly to indicalle this fact.

\section{Materials and Methods}

Plant material. All experiments were carried out with 'Owari' satsuma mandarin (Citrus unshiu Marc.). Under the climatic conditions of our experiments this cultivar behaves as a regular bearer from year to year. Fruit are harvested from early October to late December. Flower induction, as assessed by the flowering behavior of the buds when cultured in vitro, occurs from early December until mid or late January (Iwahori et al., 1990; GarciaLuis et al., 1992b). Adult trees of this cultivar on sour orange rootstock (Citrus aurantium L.) and with a heavy load of fruit (100 $\mathrm{kg} /$ tree; $\approx 50 \mathrm{Mg} \cdot \mathrm{ha}^{-1}$ ) were used in the experiments.

The effect of fruit removal. The effect of the timing of fruit removal on carbohydrate levels and flowering was determined in two separate experiments. The behavior of trees defruited either a few days before commercial maturity (3 Oct.; Expt. 1) or at color break (13 Oct.; Expt. 2), were compared to that of trees of the same plot harvested later in the season when the fruit was fully pigmented (5 Nov. and 9 Dec. for Expts. 1 and 2, respectively).

The effect of girdling. The effect of girdling on flowering was determined in trees harvested on 13 Oct.. at commercial maturity (early-harvested trees) or later in the season (9 Dec.; late-harvested trees). For each group of trees, three were girdled on 5 Oct., and an additional 3 on 9 Nov. Three trees from each group were selected as ungirdled controls. All scaffold branches were girdled with a sharp knife using a single cut around the branch, but no strip of bark was removed.

The effect of shading. The effect of shading (with a net that intercepted $88 \%$ of the photosynthetically active radiation) on flowering was determined with early-harvested and late-harvested trees. In the experiment with early-harvested trees, the fruit were removed on 10 Oct., and the trees were shaded for 24 days from 7 to 31 Oct. In the experiment with late-harvested trees, the fruit were removed on $10 \mathrm{Dec}$. and shading was imposed for 66 days from 5 Oct. to 10 Dec. (i.e., the end of the shading coincided with fruit removal). Half of the shaded trees were girdled on 5 Oct., and the other half were kept ungirdled; identical treatments with unshaded trees served as controls.

Experiment design. All experiments were conducted using a randomized design, with three single-tree replicates. Each tree served as a sampling unit for the determination of nonstructural carbohydrates and for the measurement of flowering.

Measurements, sampling, and analytical procedures. Leaf samples were taken from the short vegetative twigs formed during the spring-flush of growth. The following year, most of the flowers arc formed from the axillary buds from these twigs. Each sample consisted of 30 leaves sampled from all around the tree. The leaves were brought to the laboratory within 1 hour from sampling, 


\section{LEAVES}

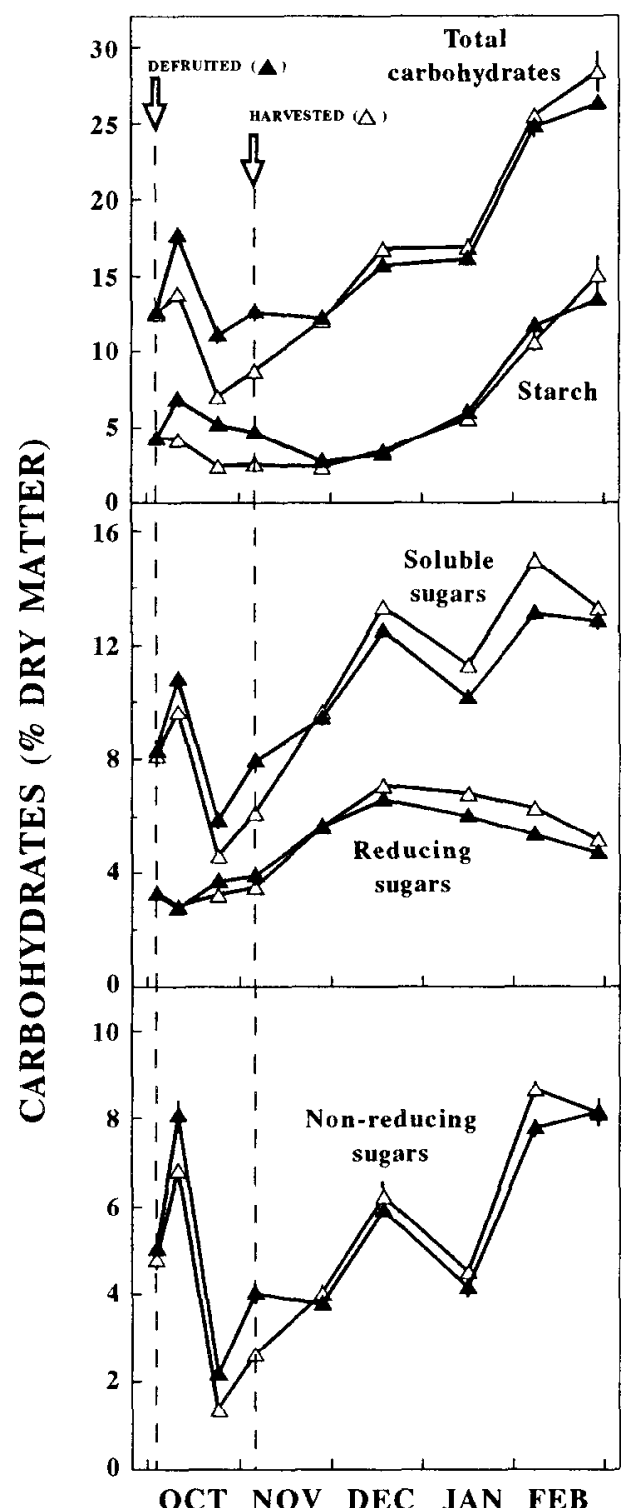

OCT NOV DEC JAN FEB
BARK

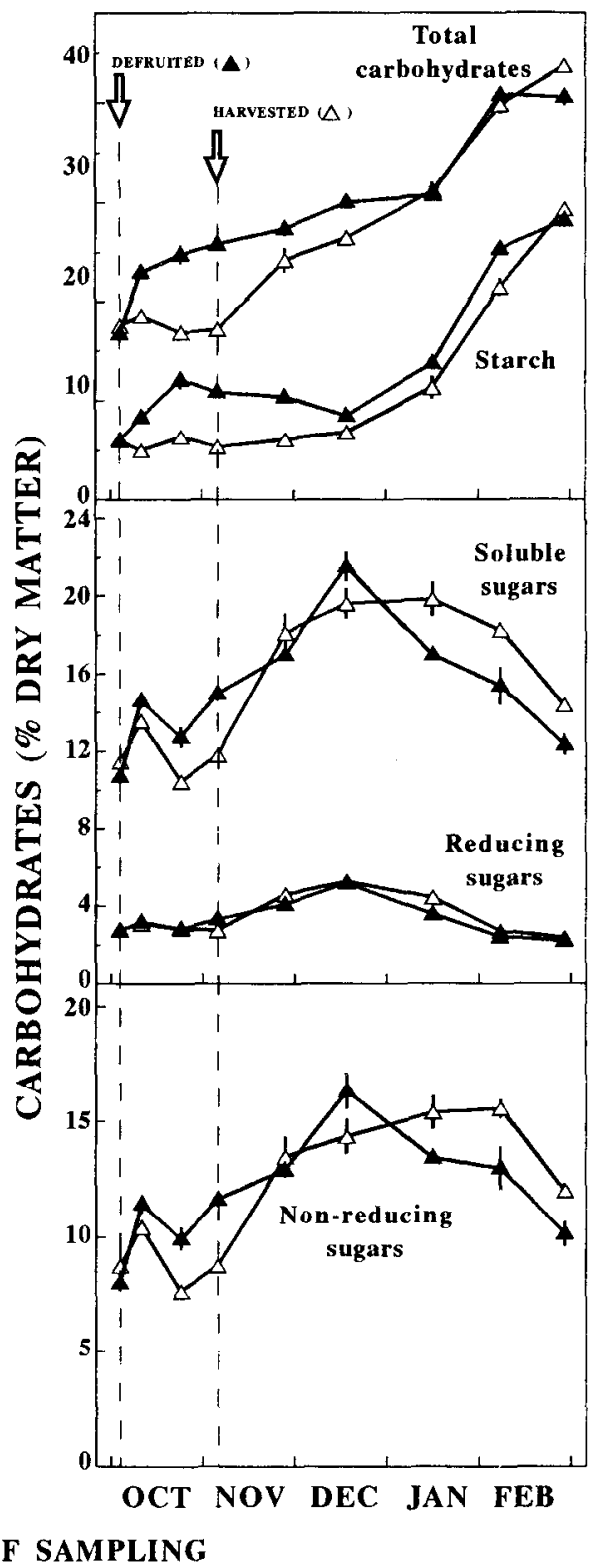

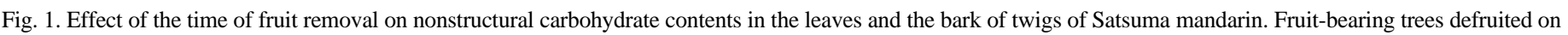
3 Oct. (s) or harvested on 5 Nov. $(\Delta)$. Means from three trees \pm SE.

washed, killed by being placed at 90C for $2 \mathrm{~h}$, dried to constant weight at $65 \mathrm{C}$, and finely ground. In one experiment, the whole twigs were sampled and the bark scraped and treated in the same way. Ethanol-soluble sugars were extracted with boiling $80 \%$ ethanol. In the clarified extract, the total sugar content was determined as described by McCready et al. (1950) and the reducing sugar content was determined as described by Park and Johnson (1949). The nonreducing sugars fraction (mainly sucrose) was estimated by difference. In the extracted sample, starch was determined as described by McCready et al. (1950).

Flowering was measured in spring by counting at least 420 nodes per tree. The shoots developed were classified according to Guardiola et al. (1977): vegetative, with no flowers; generative, consisting of a single flower; and mixed-type, with one flower in apical position along with one or several leaves. Multiple flowered inflorescences are nearly absent in this cultivar. The results of the flower counts are presented as flowers and shoots developed per
100 nodes (percentages).

The results were subjected to an analysis of variance and the effects partitioned into the main components and their interactions. Mean comparisons were performed with Student's t test. To ensure the uniformity of the variance, the transformations $\log (\mathrm{X}+1)$ or $\arcsin$ of the square root were used as appropriate.

\section{Results}

The effect of fruit removal. The removal of the fruit before commercial maturity ( 3 Oct.) caused a transient increase of starch and nonreducing sugars levels in leaves and bark compared to the trees in which the fruit were removed at commercial maturity (5 Nov.) (Fig. 1). The differences in carbohydrate levels were maximal by day 7 (leaves) or 17 (bark) after the removal of the fruit. No significant effect of fruit removal was found in the levels of reducing sugars.

Carbohydrate accumulation in the bark and leaves of the normal 
Table 1. Effect of the time of fruit removal on bud sprouting and flowering.

\begin{tabular}{lcccc}
\hline \hline & $\begin{array}{c}\text { Trees defruited } \\
\text { Parameter }\end{array}$ & $\begin{array}{c}\text { Trees harvested } \\
\text { 5 Nov. }\end{array}$ & $\begin{array}{c}\text { SE } \\
(\mathbf{n}=3)\end{array}$ & Significance \\
\hline Sprouted nodes $(\%)$ & 80 & 67 & 3 & $* *$ \\
No. of shoots/100 nodes & 101 & 76 & 9 & $*$ \\
Vegetative & 12 & 49 & 4 & $* * *$ \\
Mixed & 55 & 23 & 4 & $* * *$ \\
Generative & 34 & 3 & 6 & $* * *$ \\
No. of flowers/100 nodes & 89 & 26 & 8 & $* * *$ \\
\hline
\end{tabular}

*,**,***Significant at $P=0.1,0.05$, or 0.01 , respectively.

HARVESTED 13 OCTOBER

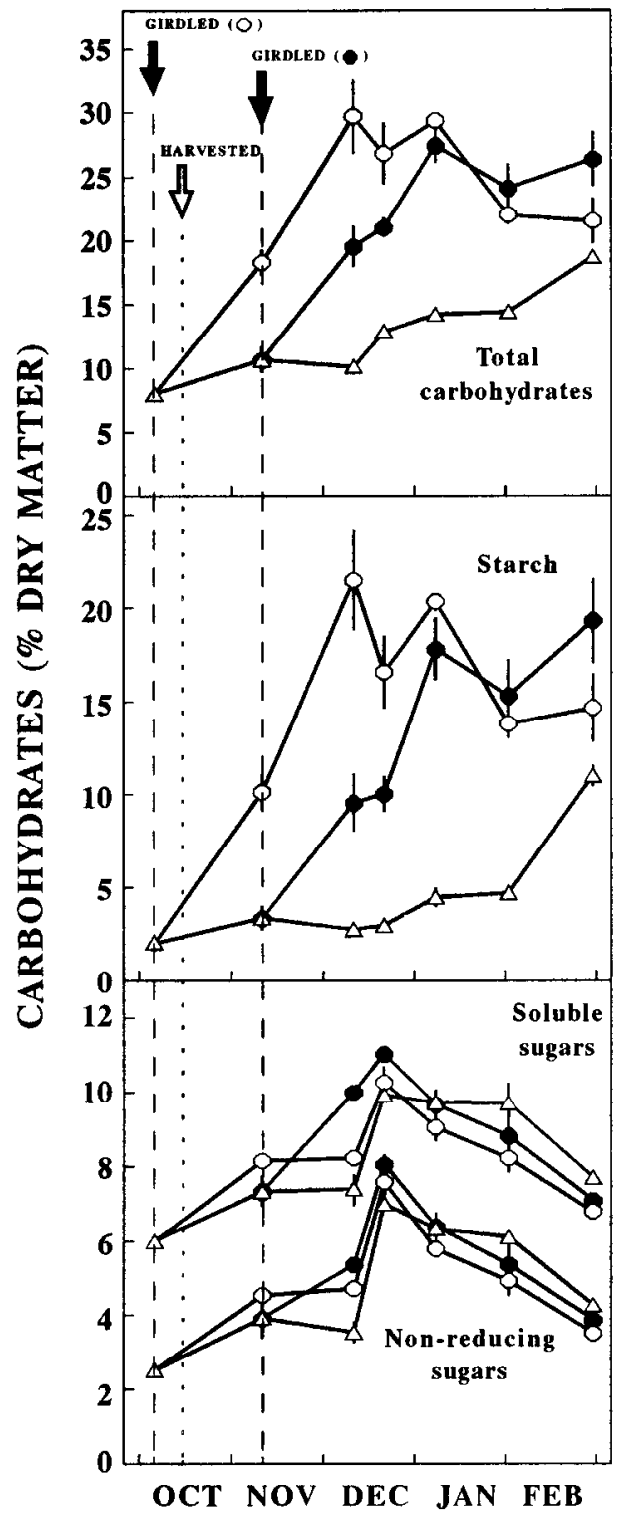

HARVESTED 9 DECEMBER

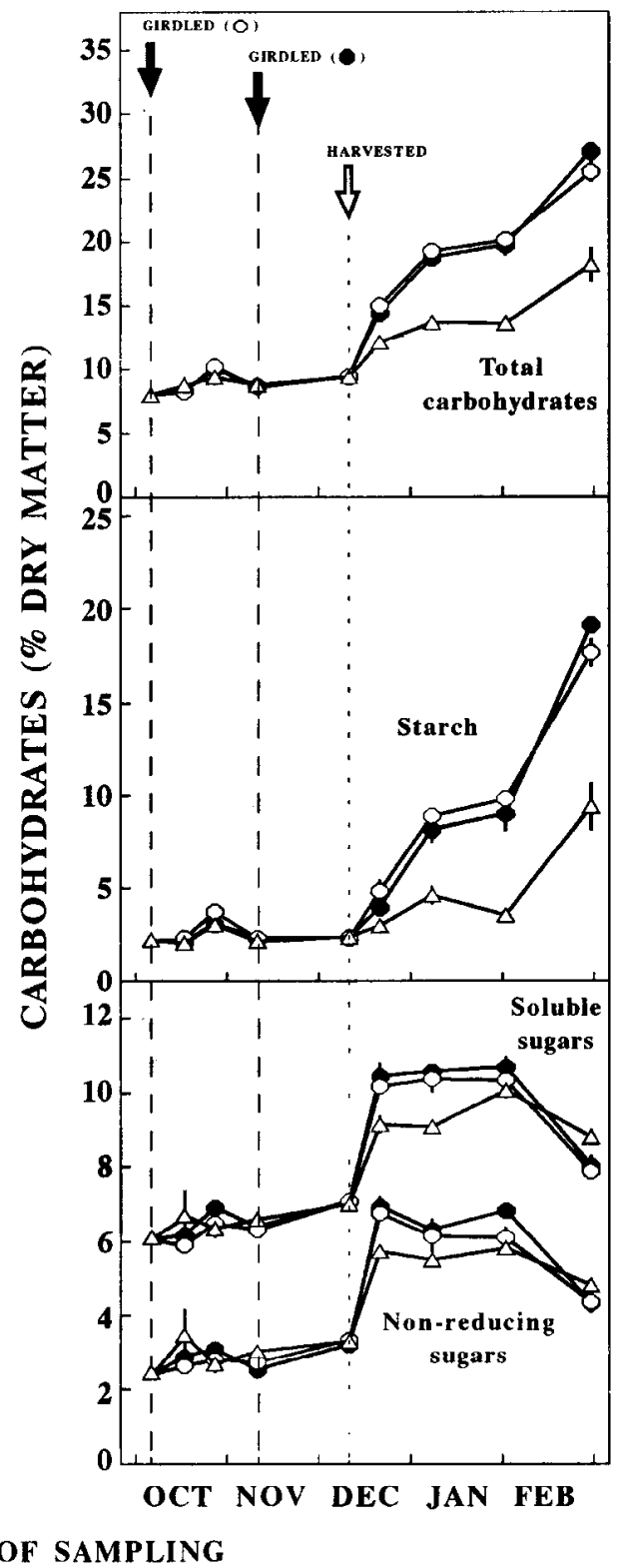

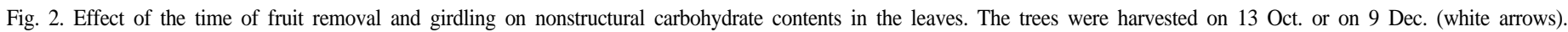

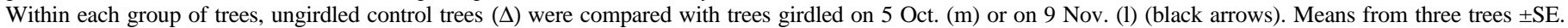

harvest trees started at the time of harvest and lasted until the end of February (Fig. 1). Soluble sugars accumulated until midDecember. After this date, starch accumulated and the soluble sugars content remained constant (leaves) or declined (bark).

Defruiting caused a 1.3-fold increase in shoot formation and a 3.4-fold increase in the number of flowers (inflorescences) (Table 1 ). The number of generative and mixed shoots was increased and that of vegetative shoots reduced. The leafy shoots (vegetative and mixed shoots) from defruited trees had a lower number of leaves (2.3 leaves/shoot) than in the normal harvest trees (5.0). 
Table 2. Effect of the time of fruit removal and girdling on bud sprouting and flowering.

\begin{tabular}{|c|c|c|c|c|c|c|c|c|c|}
\hline \multirow[b]{3}{*}{ Parameter } & \multicolumn{3}{|c|}{$\begin{array}{l}\text { Trees harvested } \\
13 \text { Oct. }\end{array}$} & \multicolumn{3}{|c|}{$\begin{array}{c}\text { Trees harvested } \\
9 \text { Dec. }\end{array}$} & \multirow{2}{*}{\multicolumn{2}{|c|}{$\begin{array}{c}\text { Significance of } \\
\text { effects }\end{array}$}} & \multirow[b]{3}{*}{ DYG } \\
\hline & \multirow[b]{2}{*}{ Control } & \multirow{2}{*}{$\begin{array}{l}\text { Girdled } \\
5 \text { Oct. }\end{array}$} & \multirow{2}{*}{$\begin{array}{l}\text { Girdled } \\
9 \text { Nov. }\end{array}$} & \multirow[b]{2}{*}{ Control } & \multirow{2}{*}{$\begin{array}{l}\text { Girdled } \\
5 \text { Oct. }\end{array}$} & \multirow{2}{*}{$\begin{array}{l}\text { Girdled } \\
9 \text { Nov. }\end{array}$} & & & \\
\hline & & & & & & & Defruited & Girdled & \\
\hline Sprouted nodes $(\%)$ & 57 & 80 & 78 & 41 & 72 & 71 & $* *$ & $* * *$ & NS \\
\hline No. of shoots/100 nodes & 67 & 143 & 112 & 46 & 94 & 98 & $* * *$ & $* * *$ & NS \\
\hline Vegetative & 7 & 5 & 2 & 15 & 0.4 & 0.2 & NS & $* *$ & NS \\
\hline Mixed & 37 & 11 & 8 & 27 & 29 & 25 & $*$ & $* *$ & $* *$ \\
\hline Generative & 22 & 125 & 102 & 5 & 64 & 72 & $* * *$ & $* * *$ & $*$ \\
\hline No. of flowers/100 nodes & 59 & 136 & 110 & 32 & 93 & 97 & $* *$ & $* * *$ & NS \\
\hline
\end{tabular}

NS, ${ }^{*}, * * * *$ Nonsignificant or significant at $P=0.1,0.05$, or 0.01 , respectively. The other effects (time of girdling) and interactions were nonsignificant.

Table 3. Effect of shading on leaf carbohydrate and flowering of defruited trees.

\begin{tabular}{lccc}
\hline \hline Parameter & Unshaded trees) & Shaded trees & Significance \\
\hline Sprouted nodes (\%) & $69 \pm 9$ & $69 \pm 4$ & NS \\
No. of shoots/100 nodes & $89 \pm 3$ & $85 \pm 12$ & NS \\
$\quad$ Vegetative & $6 \pm 1$ & $14 \pm 3$ & $*$ \\
$\quad$ Mixed & $42 \pm 11$ & $38 \pm 4$ & NS \\
$\quad$ Generative & $42 \pm 8$ & $33 \pm 10$ & NS \\
No. of flowers/100 nodes & $83 \pm 3$ & $71 \pm 9$ & NS \\
Carbohydrates in leaves $(\%$ dry matter) & $5.2 \pm 0.49$ & $1.6 \pm 0.06$ & $* * *$ \\
$\quad$ Starch & $4.3 \pm 0.12$ & $4.2 \pm 0.05$ & NS \\
Reducing sugars & $3.73 \pm 0.08$ & $1.28 \pm 0.06$ & $* * *$ \\
$\quad$ Nonreducing sugars & $13.2 \pm 0.67$ & $7.1 \pm 0.08$ & $* * *$
\end{tabular}

${ }^{7}$ Fruit harvested on 10 Oct.: shading imposed from 7 to 31 Oct.

'Means from three trees $\pm \mathrm{SE}$.

${ }^{\mathrm{x}}$ Samples picked on 20 Oct.

NS,***,***Nonsignificant or significant at $P=0.1,0.05$, or 0.01 , respectively.

A similar effect on leaf carbohydrate levels was found in the second defruiting experiment, the early fruit removal causing a transient accumulation of starch and nonreducing sugars in leaves (Fig. 2). The effect on flowering was smaller in this experiment, in which the trees were defruited at a later date than in the first experiment. The early harvest of the trees caused a 1.8-fold increase in flower number, but the reduction in the number of vegetative shoots was not statistically significant (Table 2).

The effect of girdling. The effect of girdling on carbohydrate accumulation in the leaves was influenced by the fruit. In fruitbearing trees, no differences in carbohydrate levels were detectable until harvest. The removal of the fruit caused an immediate increase of nonreducing sugars levels and a faster rate of starch accumulation in leaves of girdled trees as compared to the ungirdled controls (Fig. 2). The differences in starch content persisted until the end of February, when sampling was discontinued.

In defruited trees, girdling resulted in an immediate accumulation of starch and nonreducing sugars in the leaves well above the values in the untreated controls (Fig. 2). Girdling also changed the time course of carbohydrate accumulation. October-girdled trees reached the maximum starch contents in leaves in early December. Afterward there was a decreasing trend of starch and nonreducing sugars in the leaves, which fell below the levels found in November-girdled trees. The accumulation of carbohydrates in the control trees showed the same trend described above. The rate of starch accumulation in leaves increased by mid-December, but the levels at the end of February were lower than in the girdled trees. Neither the time of fruit removal nor girdling affected the reducing sugar levels in leaves which ranged between $3 \%$ to $4 \%$ (data not shown).
In the early- and late-harvested trees, girdling increased bud sprouting, shoot formation, and flower formation and reduced the number of vegetative shoots (Table 2). The increase in flower formation resulted from the increase in the number of generative shoots, whereas, in the early defruited trees, girdling reduced the number of mixed shoots. Similar sprouting and flowering behavior was found in early-girdled (5 Oct.) and late-girdled (9 November) trees.

The effect of shading. The shading of defruited trees markedly reduced the nonreducing sugar and starch levels of the leaves, but had no effect on reducing sugar levels (Table 3). These differences disappeared within 10 days after the screen was removed (data not shown). Effects on bud sprouting and flowering were small. The only significant shading effect seen on shoot development was a slight increase in the number of vegetative shoots (Table 3 ).

In fruit-bearing (late defruited) trees. shading reduced leaf starch and nonreducing sugar below unshaded controls (Fig. 3). The reduction in starch was statistically significant $(P<0.05)$ but quantitatively small, since starch levels in the unshaded controls were very low. Irrespective of shading, no effect of girdling on leaf carbohydrate levels was detectable before harvest. Starch and soluble sugars accumulated rapidly after fruit removal, at the time shading was discontinued. The rate of starch accumulation and, transiently, nonreducing sugar levels, were higher in the girdled trees. In the nongirdled trees, starch and nonreducing sugars were transiently higher in the previously shaded trees. but the differences disappeared by early February. Shading had no effect on the subsequent carbohydrate accumulation in the leaves of girdled trees. Reducing sugar levels were unaffected by the girdling and shading treatments and remained nearly constant throughout the 


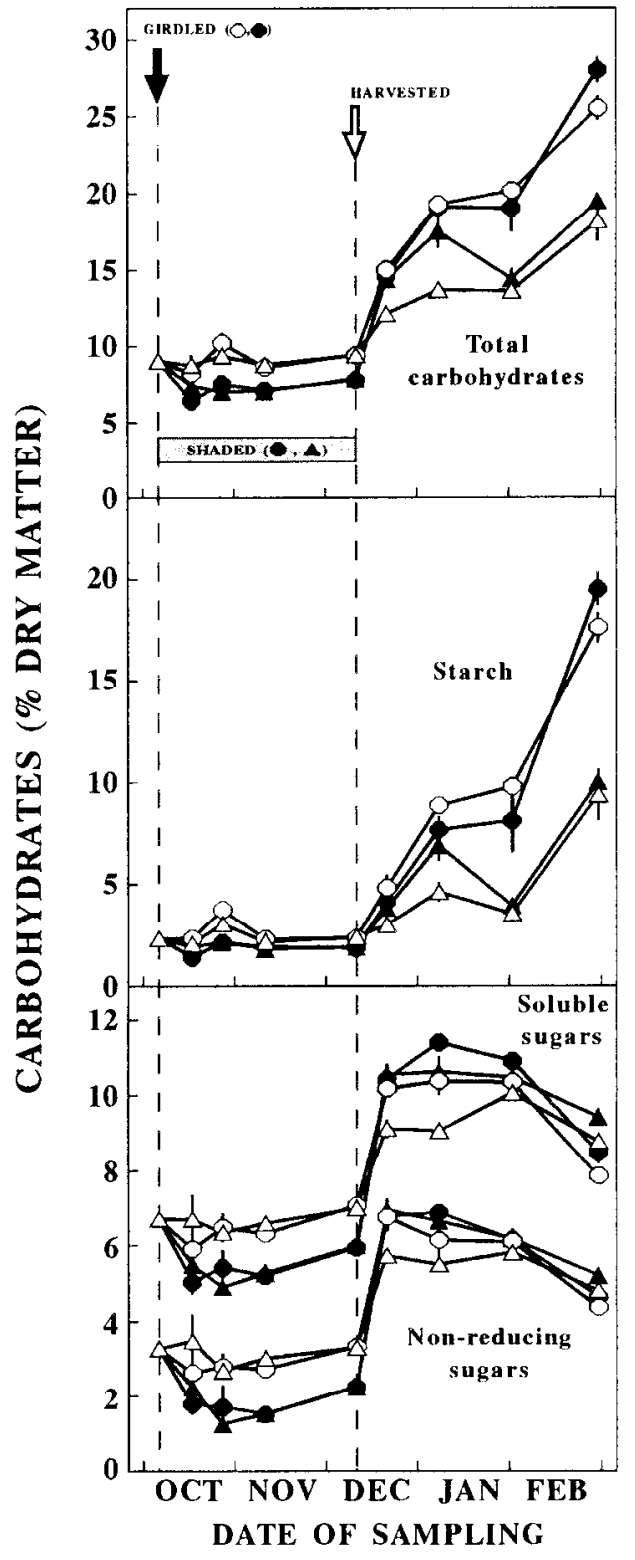

Fig. 3. Effect of shading on nonstructural carbohydrate contents in the leaves of ungirdled $(\Delta, \mathrm{s})$ and girdled $(\mathrm{m}, \mathrm{l})$ trees. Trees girdled on 5 Oct. Shading $(\mathrm{s}, \mathrm{l})$ was imposed frrom 5 Oct. until fruit harvest $(10 \mathrm{Dec}$.). Means from three trees $\pm \mathrm{SE}$.

sampling period within the range of $3 \%$ to $4.5 \%$ (data not shown).

The effects of shading on bud sprouting and flowering added to the effects of girdling. Shading reduced bud sprouting and the number of generative shoots, and had no effect on the number of other shoot types (Table 4). Girdling increased bud sprouting and flower formation, and reduced the number of vegetative shoots.

\section{Discussion}

It was the most powerful sink for carbohydrates in our experiments, and prevented the storage of reserves in leaves and bark (Fig. 1) and transport to the roots (unpublished data). Therefore, girdling the fruit-bearing trees had no significant effect on carbohydrate accumulation in the leaves until fruit harvest (Figs. 2 and 3 ). When the fruit were removed, carbohydrate accumulation in the leaves was greatly enhanced by girdling (Fig. 2). In unmanipulated defruited trees, carbohydrate levels in the leaves increased after November, coinciding with the seasonal decrease in temperature (Figs. 1 and 2), which fell gradually from a mean value of $15.6 \mathrm{C}$ in November to $10.9 \mathrm{C}$ in January. The design of our experiments resulted in differences in carbohydrate contents in the leaves either before and/or during chilling, and in this way the role of carbohydrate levels on flower formation during these two stages of bud development could be assessed.

The increase in flower formation caused by the early removal of the fruit in this study followed the pattern described earlier (Garcia-Luis et al., 1986). The fruit reduced bud sprouting and inhibited flower induction, which resulted in an increase in vegetative shoot formation. The effect of fruit removal on flowering was greater when performed before commercial maturity (Table I), but a significant effect (50\% reduction in flowering) also was obtained at a later date (Table 2). Despite the differences in flowering, the differences in carbohydrate contents in the leaves were relatively small. Since carbohydrate contents in leaves and bark during chilling and up to the time of bud sprouting were identical in early defruited and normal harvested trees, any influence of the fruit on flowering through the carbohydrate levels in the leaves must have been exerted before chilling.

The reduction of flowering by shading (Tables 3 and 4) could be interpreted as indicative of a sensitivity of the buds to carbohydrate supply before chilling, but in our experiments there was no quantitative relationship between prechilling carbohydrate levels and flowering. Shading of the nonfruiting trees during October resulted in a higher reduction in leaf carbohydrates (Table 3) than that caused by the fruit (Fig. I), yet shading resulted in a lower reduction in the number of flowers (up to $15 \%$; Table 3 ) than caused by the fruit (71\%; Table 1). Furthermore, the increase in flowering by girdling in defruited trees was similar regardless of the time of girdling (Table 2), whereas starch and nonreducing sugar levels in leaves during October and November were much higher in the October-girdled than in the November-girdled trees (Fig. 2).

Table 4. Effect of shading on bud sprouting and flowering in ungirdled and girdled fruiting trees. ${ }^{2}$

\begin{tabular}{|c|c|c|c|c|c|c|}
\hline \multirow[b]{2}{*}{ Parameter } & \multicolumn{2}{|c|}{ Nongirdled trees } & \multicolumn{2}{|c|}{ Girdled trees } & \multicolumn{2}{|c|}{ Significance of effects } \\
\hline & Control & Shaded & Control & Shaded & Girdling & Shading \\
\hline Sprouted nodes $(\%)$ & 41 & 33 & 12 & 51 & $* * *$ & $* *$ \\
\hline No. of shoots/100 nodes & 46 & 35 & 94 & 64 & $* * *$ & $*$ \\
\hline Vegetative & 15 & 18 & 0.4 & 0.6 & $* * *$ & NS \\
\hline Mixed & 27 & 16 & 29 & 36 & NS & NS \\
\hline Generative & 5 & 0 & 64 & 26 & $* * *$ & $* * *$ \\
\hline No. of flowers/100 nodes & 32 & 16 & 93 & 62 & $* * *$ & NS \\
\hline
\end{tabular}

${ }^{7}$ Trees girdled on 5 Oct. Shading imposed from 5 Oct. to 9 Dec. Fruit harvested on 9 Dec.

ss,$* * * * * *$ Nonsignificant or significant at $P=0.1,0.05$, or 0.01 , respectively. The interactions were nonsignificant. 
Carbohydrates (mainly starch) accumulated in the leaves during chilling (Figs. 1-3), and this accumulation was greatly enhanced by girdling (Figs. 2 and 3). Although correlations between carbohydrate (starch) levels in the leaves during winter and flower formation have been often reported (Davenport, 1990), our present results and previously published evidence demonstrate that the effect of girdling on flowering can not be explained solely in terms of carbohydrate accumulation.

Girdling was equally effective in increasing flowering in early harvested and in late harvested trees (Table 2). However, since the rate of carbohydrate accumulation was different for both treatments (Fig. 2), the role of carbohydrate accumulation before January on flower formation is not clear. Further, defoliating the twigs in mid December had no effect on flowering in this cultivar (Garcia-Luis et al., 1988), and girdling satsuma trees in late November was ineffective in enhancing flowering (Iwahori et al., 1990; Agustí et al., 1993). Although no quantitative determinations were performed by these authors, we might expect that starch accumulated at a similar rate as in our girdled late-harvested trees. It seems, therefore, that girdling acts on the buds during October and November, and that the mechanism of action is largely unrelated to carbohydrate accumulation at a later date. Rapid responses of the buds to girdling have been reported. Iwahori et al. (1990) found that the buds of September girdled trees showed a deeperdormancy by mid-October than buds from control ungirdled trees. Flower induction was advanced by girdling, to start in midNovember and to be completed by mid-December, one month earlier than in the ungirdled controls (Iwahori et al., 1990; GarciaLuis et al., 1992b).

In many species (Bernier et al., 1981; Dickens and van Staden, 1988), including citrus (Garcia-Luis et al., 1989). the carbohydrate requirements seem to be higher for flower formation than for vegetative shoot development as demonstrated through in vitro studies with excised buds. Also, very low carbohydrate levels, as caused by a long-term (4-month) shading during winter, almost suppresses flower formation in citrus (Deidda and Agabbio, 1977). Although in all our experiments the flower-enhancing treatments invariably caused an accumulation of carbohydrates in the leaves at some moments above the respective controls, we could not always correlate flower number with carbohydrate levels at a particular stage of flower formation. Overall, the experiments did not provide evidence therefore that carbohydrate levels in the leaves were limiting flower formation nor did carbohydrates act as the main regulatory factor for the effect of the fruit and girdling on flower formation in satsuma mandarin.

\section{Literature Cited}

Augusti, M., V. Almela, and J. Pons. 1992. Effects of girdling on alternate bearing in citrus. J. Hort. Sci. 67:203-210.

Becerra. S. and J.L. Guardiola. 1984. Inter-relationship between flowering and fruiting in sweet orange, cultivar Navelina. Proc. Intl. Soc. Citricult. 1: 190-194.

Bernier. G., J.M. Kinet, and R.M. Sachs. 1981 The physiology of flowering. vol. 2. CRC Press, Boca Raton, Fla.

Cohen, A. 1981. Recent developments in girdling in Citrus trees. Proc. Intl. Soc. Citricult. 1:196-199.

Davenport, T.L. 1990. Citrus flowering. Hort. Rev. 12:349-408.

Deidda, P. and M. Agabbio. 1977. Some factors influencing flowering and fruit-setin Clementina mandarin. Proc. Intl. Soc. Citricult. 2:688-692.

Dickens, C.W.S. and J. van Staden. 1988. The induction and evocation of flowering in vitro. S. Africa J. Bot. 54:325-344.

Emer, Y. 1988. Effects of girdling on the differentiation of inflorescence types and fruit set in Shamouti orange trees. Israel J. Bot. 37:173-180. Fishler, M., E.E. Goldschmidt, and S.P. Monselise, 1983. Leaf area and fruit size in girdled grapefruit branches. J. Amer. Soc. Hort. Sci. 108:218-221.

Furr, J.R. and W.W. Armstrong. 1956. Flower induction in Marsh grapefruit in the Coachella Valley, California. Proc. Amer. Soc. Hort. Sci. 67:176-182.

García-Luis, A., V. Almela, C. Monerri, M. Agusti, and J.L. Guardiola. 1986. Inhibition of flowering in vivo by existing fruits and applied growth regulators in Citrus unshiu. Physiol. Plant. 66:515-520.

García-Luis, A., F. Fornes, A. Sanz, and J L. Guardiola. 1988. The regulation of flowering and fruit set in Citrus: relationship with carbohydrate levels. Israel J. Bot. 37:189-201,

García-Luis. A., M. Kanduser, P. Santamarina, and J.L. Guardiola. 1992a. Low temperature influence on flowering in Citrus. The separation of inductive and bud dormancy releasing effects. Physiol. Plant. 86:648-652.

García-Luis, A., M. Kanduser, M. Sánchez-Perales, P. Santamarina, and J.L. Guardiola. 1992b. The characterization of the inductive effect of low temperature on flowering in Citrus. Proc. Intl. Soc. Citricult., Acireale (In press.)

Garcis-Luis. A., P. Santamarina, and J.L. Guardiola. 1989. Flower formation from Citrus unshiu bud cultured in vitro. Ann. Bot. 64:515-519.

Goldschmidt, E.E., N. Aschkenazi, Y. Herzano, A.A. Schaffer, and S.P. Monselise. 1985. A role for carbohydrate levels in the control ot flowering in citrus. Scientia Hort. 26:159-166.

Goldschmidt, E.E. and A. Golomb. 1982. The carbohydrate balance of alternate-bearing Citrus trees and the significance of reserves for flowering and fruiting. J. Amer. Soc. Hort. Sci. 107:206-208.

Guardiola, J.L., M. Agustí, and F. Garcia-Marí. 1977. Gibberellic acid and flower bud development in sweet orange. Proc. Intl. Soc. Citricult. 2:696-699.

Guy, C.L., G. Yelenozky, and H.C. Sweet. 1981. Distribution of ${ }^{14} \mathrm{C}$ photoynthetic assimilates in 'Valencia' orange seedlings at 10 and 25C. J. Amer. Soc. Hort. Sci. 106:433-137.

Iwahori, S., A. Garcia-Luis, P. Santamarina,C. Monerri.and J.L. Guardiola. 1990. The influence of ringing on bud development and flowering in Satsuma mandarin. J. Expt. Bot. 41:1341-1346.

Jones, W.W., T.W. Embleton. M.L. Steinacker, and C.B. Cres. 1970. Carbohydrates and fruiting of 'Valencia' orange trees. J. Amer. Soc. Hort. Sci. 95:380-381

Lenz, F. and U. Küntzel. 1974. Carbohydrate content of citrus leaves as affected by fruit load. Gartenbauwissenchaft 39:99-101.

Lewis, L.N.. C.W. Coggins, and H.Z. Hield. 1964. The effect of biennial bearing and NAA on the carbohydrate and nitrogen composition of Wilking mandarin leaves. J. Amer. Soc. Hort. Sci. 84:147-151.

Lovatt, C.J., Y. Zheng, and K.D. Hake. 1988. A new look at the KrausKraybill hypothesis and flowering in citrus. Proc. 6th Intl. Citrus Congr. $1: 475-483$.

McCready, R.M.. J. Guggolz, V. Silveira, and H.S. Owens. 1950. Determination of starch and amylose in vegetables. Application to peas. Anal. Chem. 27: 1156-1158.

Monbelise. S.P. 1085. Citrus and related genera. vol. 2, p.275-294. In: A.H. Halevy (ed.). Handbook of flowering. CRC Press, Boca Raton, Fla. Moss, G.I. 1969. Influence of temperature and photoperiod on flower induction and inflorescence development in sweet orange (Citrus sinensis L. Osbech). J. Hort. Sci. 44:311-320.

Moss, G.I. 1971. Effect of fruit on flowering in relation to biennal bearing in sweet orange (Citrus sinensis). J. Hort. Sci. 46:177-184.

Ogahi, C., K. Fujita. and H. Ito. 1963. Investigations on the cause and control of alternate bearing in unshiu orange trees. IV. Nitrogen and carbohydrate levels in the shoots as related to blossoming and fruiting. J. Jap. Soc. Hort. Sci. 32: 157-167.

Park, J.T. and M.J. Johnson. 1949. A submicrodetermination of glucose. J. Biol. Chem. $181: 149-151$

Southwich, S. and T.L. Davenport. 1986. Characterization of water stress and low temperature effects on flower induction in Citrus. Plant Physiol. $81: 26-29$.

Yelenosky, G. and C.I. Guy. 1977. Carbohydrate accumulation in leaves and stems of 'Valaicia' orange at progressively colder temperatures. Rot. Gaz. 138:13-17. 